\title{
IS LEPROSY TRANSMITTED BY ARTHROPODS?
}

\author{
by Prof. Nitls Dungal, \\ Prof. of Pathology, University of Iceland, Reykjavik \\ (Paper delivered at a Symposium on Leprosy Research, London, \\ June 10, under the auspices of the Acid-Fast Club of London \\ and International Academy of Pathology)
}

\section{Introduction}

About 1900 the distinguished Danish dermatologist EHLERS visited 3 different islands in which leprosy was endemic, namely lceland with 181 known cases and an estimated number of 200 , St. Croix in the Caribbean with 87, and Crete with about 600 . Prof. Ehlers advised antileprosy measures for all three islands comprising the building of a leprosy hospital and the segregation of every new case. This was carried out, but the result was very variable. Thus in Iceland the leprosy hospital was built, and came into use in 1897, and leprosy decreased rapidly in the ensuing 20 years and had practically died out by 1940, and now there are only 4 patients left, i.e. 4 patients in a total population of 170,000 against 200 in 70,000 population in 1900. In St. Croix the results were very disappointing, and leprosy still remains a health problem. Knott in 1936 had occasion to deplore the inefficiency of the measures taken. The leprosarium was built in 1910 and since 1918 a total of 88 cases were found up to 1936, bringing the total known cases up to 99 . In spite of good economic conditions and good nutrition the leprosy continued to spread.

In Crete, leprosy gradually decreased until in 1957 the leprosarium could be emptied.

In Norway, the course of the leprosy has been similar to that in Iceland, in that there has been segregation in the hospital at Bergen and from a fair incidence about 1900 it has declined to nil nowadays. But in the Philippines, after 40 years of segregation, leprosy has not declined. So segregation is successful in some countries but not in others. As long as we cannot point out the reasons for the discrepancy we are entitled to suspect that some factors operate which we do not know and do not understand.

Chaussinand ${ }^{2}$ thinks that tuberculosis and leprosy are competitive antagonists. This theory would explain much, but is difficult to prove, as we know too little about the dissemination of tuberculosis in Europe in the last two centuries, when leprosy was declining. Certainly in Iceland it is certain that the decline of leprosy had nothing to do with a spread of tuberculosis. Great numbers of adults were unaffected by tuberculosis. Magnusson ${ }^{2}$ reports that in 1921-30 the percentage of non Pirquet positives at the age of 14 reached only $30 \%$, and at age 20 only $50 \%$ were tuberculin positive when leprosy 
in Iceland was dying out. Leprosy certainly does not inhibit the progress of tuberculosis as BJARNIIIIJINSSON ${ }^{32}$ indicates from his study of autopsies on 111 leprosy patients, in whom 24 showed signs of healed tuberculosis and 20 had died of that disease. The cause of the decline and disappearance of leprosy must be sought elsewhere than in the idea of an immunization of the population against leprosy by a widespread dissemination of tuberculosis.

The main problem in the epidemiology of leprosy still remains, as 80 years ago, how do the bacilli eitter the human body and produce leprosy?

Chaussinani ${ }^{2}$ and many others with him have incriminated the inhalation of nasal droplets of mucus from infective patients, as in tuberculosis. But if this were so leprosy should be much more widespread and should occur even in hospital staff, which does not occur. Leprosy is not a lung disease, nor are nasal lesions so common in many countries. In the Nauru epidemic, BrAY ${ }^{3}$ found the nasal mucus free of acid-fast bacilli in nearly all cases, and Dr. Bjarnhedinsson, who was in charge of the leprosarium in Iceland, told me that nasal lesions were so seldom found there that he doubted their importance in the spread of the disease. Also in Iceland fresh cases were found at all ages and were not peculiar to infancy and childhood. FLOCH ${ }^{4}$ found the same thing in Cayenne, where $81 \%$ of cases first showed the disease at ages 40 to 60 .

It is generally maintained that there is little danger of infection unless the contact is long and close, such as found by BoENJAmin. ${ }^{5}$ Yet several cases are on record where the contact has been short and not very close. In Colombia there are certain "casas malditas", houses under a curse, where danger of contracting leprosy is believed to follow the spending of a night there. There are a few cases of accidental transfer of leprosy, as the case reported by MARCHOUX ${ }^{6}$ of a surgical assistant having been infected by a needle prick; and the case of KLINGMÜLLER ${ }^{4}$ of infection by a hypodermic needle previously used on a lepromatous case in reaction; also PorRetT and OLSEN ${ }^{8}$ who reported the case of leprosy in a tattoo mark in two sailors in Australia in 1943. In Colombia ${ }^{22}$ there is the case of a pinprick apparently having transferred the disease to a boy of 17 , and even inoculation by scratching ( FENNEL $^{12}$ ) seems possible, as in a case of habitual scratching of the same place in the head by a contact, and later a leprotic granuloma developed in that site years later. Arning's well-known experiment to graft leprotic material and so infect a subject is of little value to our understanding as to how the disease is spread. DanielsSen ${ }^{9}$ and Mouritz ${ }^{10}$ carried out unsuccessful inoculation experiments. It is surprising leprosy is not much more widespread in natural conditions, considering how many are the sources of infection. In a household, many will escape. AYCOCK and MCKINLEY ${ }^{11}$ report that Gwyther found that only 4 
of 178 women living with male leprosy subjects developed the disease, and conjugal leprosy occurred in $4.8 \%$ of women and $5.1 \%$ of men.

\section{Unexplained Problems of Epidemiology}

There are many cases where contact is unknown or cannot be recollected, and many cases where the transfer of the infection cannot be pinpointed. It may be easier to collect information in northern countries, and difficult to gain information in tropical countries densely populated, but KNOT ${ }^{1}$ from St. Croix reported several cases of leprosy in children who apparently never had contact with leprosy patients, except that there was a relative with leprosy who died before the children were born. This problem caused Knott to postulate a subclinical form of leprosy. Knott also reported cases of transient leprosy who made spontaneous recovery.

In Iceland the following cases are recorded:-

1. J.N., a male of 27 years with anaesthetic leprosy. At the age of 20 he slept one night in the same room as a leprosy patient, but not in the same bed, otherwise no history of contact with the disease. Two years later nerve pains began.

2. J.H., a male of 35 years with nodular leprosy who was a farm worker 10 years ago for 2 years. A year after he left the farmer's wife developed leprosy.

3. S.S., a male of 35 years with mixed nodular leprosy. About 7 to 8 years ago he slept in a large room where a leprosy patient slept in another bed. Then $2 \frac{1}{2}$ years later small nodules appeared on the dorsum of the right foot, and these later increased in size and multiplied.

4. T.S., a male of 36 years with nodular leprosy. He shared a bed 20 years ago with a man who later developed leprosy and there was no history of other contact with leprosy.

5. J.Th., a male of 32 years with nodular leprosy. At the age of 13 he shared a bed with a man who later developed leprosy and there was no history of other contact with leprosy.

6. P.J.H., a male of 53 years who gave no history of contact with leprosy, but who associated with a woman who developed leprosy after they parted.

FAGERHOLM $^{13}$ reports a striking problem of epidemiology. On a small island in the Baltic, off the coast of Finland, about 10 miles, a single family lived, with no other people on the island. This family left and was replaced by another family, this happening several times, and four housewives developed leprosy in succession, though all the families came from regions on the mainland where there was no leprosy. Dr. Fagerholm suggests a transmission through furniture or 
household articles of a type mainly used by the women. Children are not mentioned in these families.

\section{Insects as Possible Vectors}

In 1911 EhLERS, Bourret and WITH ${ }^{14}$ wrote a paper on the possibility of propagation of leprosy by arthropods. They reared several kinds of arthropods and caused them to bite leprosy patients of lepromatous type, and dissected out and stained the stomachs for acid-fast bacilli. They found only 1 in 21 of Pulex irritans and 1 in 12 of Stegomyia fasciata were positive, and 53 bed bugs and 16 head lice were negative. They thought that leprosy was probably not transmitted by insects.

SANDES ${ }^{15}$ starved certain insects and fed them on leprosy patients. He found acid-fast bacilli in 1 in 80 mosquitoes, in 20 of 60 fleas, and in 20 of 75 bed bugs. Later he found acid-fast bacilli in $30 \%$ of bed bugs, not only in their stomach contents, but also in other stomach fluids, and thought there were some signs of growth of the bacilli in the bed bugs. When bed bugs containing leprosy bacilli bit a patient with anaesthetic leprosy, a papule arose round the bite in which papule bacilli were absent but were found peripherally. It was impossible to decide whether these bacilli were inoculated or derived from the patient.

De Souza-Araujo ${ }^{16}$ found acid-fast bacilli in the blood-sucking garrapatas (Amblyoma cajennense) removed from leprosy patients and thinks they may transfer leprosy. BorReL ${ }^{17}$ thought Acarus scabiei and Demodex folliculorum to be possible transmitters. Transmission of leprosy by insects is difficult to prove so long as we cannot cultivate the bacillus nor transmit it to experimental animals. We thought it worth while therefore to compare data from Iceland with the data of other countries. Possible insect vectors are few in Iceland but numerous in other countries, so we enquired of 62 leprosaria in other countries about their insect species, and whether few or abundant. From 42 countries we received replies which showed that $P$. capitis and $P$. pubis existed in all the countries, and $P$. vestimentorum was absent in 21 , Pulex irritans and Sarcoptes scabiei were more or less frequent in 93 to $95 \%$ of leprosy countries. It seemed from the replies that no flying insect could be the sole vector of leprosy, nor is it likely that it transfers the disease at all. In Iceland the bed bug does not exist, which of course does not absolve it from being a possible vector elsewhere. The body louse probably does not transmit leprosy, for leprosy occurs in naked tribes, and naked tribes have no body lice, and leprosy was found in 9 out of 14 territories where the people go naked.

It is generally admitted that leprosy is a house-bound disease. The old idea that it is hereditary originates in its house and family incidence, though as a rule the spread of the disease is limited to the 
household. TALWIK ${ }^{19}$ reports of the island of Osel in the Baltic that leprosy concentrates on a small peninsula, tending to limit itself to small groups, mostly to single farms, and sharing a home seems of the greatest importance to the spread. "A house or farm in which a leprosy patient lives or stays becomes sooner or later a breeding place for new infections". The same was our experience in Iceland, certain houses and farms seeming to be breeding places of leprosy, and recalling the "malas habitaciones" or "casas malditas" of Colombia previously mentioned.

Housebound insect vectors might explain this close connection with houses, especially where infections seem to occur in a house which has been vacated by the previous occupants. Cockroaches, bed bugs, and houseflies are ubiquitous. The former two do not occur in Iceland, and the housefly is not a very likely vector, as it does not bite.

The biting insects are more likely as vectors, such as the flea, the louse, and Acarus scabiei.

The flea has long been suspected. CARRASQuILla ${ }^{23}$ in 1905 thought of it, but as no direct proof could be brought, in the course of time the charge was dropped, until in 1942 MuÑos Rıvas of Colombia revived it. He had found that the incidence of leprosy in various parts of Colombia corresponded mainly with the humid regions where fleas abound in the primitive and dirty huts of the poor people. He examined fleas from leprosy environments and from those free of leprosy and found acid-fast bacilli in 11 to $16 \%$ of the former, and none in the latter. ${ }^{21},{ }^{22} \mathrm{He}$ found the bacilli in larvae developed from infected fleas in $2.36 \%$, but none in the larvae from uncontaminated fleas. (Fleas can live up to 500 days.) OCKLAND ${ }^{24}$ has pointed out how frequent fleas were in Norway during the time when leprosy was relatively prevalent, especially in the humid climate of the west coast, where leprosy was prevalent in dirty lodgings of the poor. Now in Norway housing conditions are good, fleas have disappeared, and leprosy is practically eradicated. In Iceland fleas were very frequent at the time leprosy was prevalent, but Pulex irritans seems now to have disappeared completely. In former times the use of sheepskins in the beds seems to have been associated with an abundance of fleas. Fleas are apt to be associated with dirty dwellings, with every animal having its own type of flea, except monkeys, on whom fleas do not thrive. Most initial lesions of leprosy occur on uncovered skin, and in tropical countries the initial lesions may be almost anywhere, whereas I find from the records in Iceland that initial lesions are in the face, feet, hands, and legs, but more rarely on the thighs and trunk. It may be a matter of more covering of clothes. In the case of sharing a bed, the initial lesions are anywhere.

Sometimes a flea may bite several times without being able to draw blood. SNOdgrass ${ }^{25}$ and WeNk ${ }^{26}$ have made detailed studies, 
from which it emerges that the biting apparatus not only can drill its way in very rapidly, and through the salivary tube saliva is pumped downwards during the bite without any admixture of blood. Bacilli from the host can easily stick to the lacinia and epipharynx. Any haemorrhage or exudate around the inoculated bacilli may inhibit the inoculation of the bacilli. MourITZ ${ }^{10}$ and $\mathrm{WADE}^{27}$ described inoculation experiments with great numbers of bacteria, with negative results; it might be connected with the factor of the action of haemorrhage or exudate. The cases of the positive results from tattooing and accidental needle pricks might also be based on this factor, that a bloodless prick may be more effective. The flea can produce both bloodless and haemorrhagic pricks, and probably the pumping in of saliva has little influence. A simple dry prick into the dermis may be all that is necessary. Of all the biting parasites of man the flea lives longest, for weeks, months, or even a year. It may stay hungry for weeks waiting for a chance to draw blood, and if the flea were a transmitter of leprosy we can imagine the part it could play in the case of the sharing a bed with a leprosy subject. The flea may be the explanation why people can be infected in a house after the patients have left. The bacilli may remain attached to the piercing equipment of the flea and stay alive for weeks when the flea has nothing to bite. The bacilli may be able to keep alive for some time on the indented surface of the lacinia of the flea, in conditions of humidity and darkness.

The louse. Much of what has been said about the flea also applies to the louse. However, the louse has to live all its life on the host, and bites its host at least once or twice a day, and the crab louse may suck blood for hours. Lice die if they have to live without blood for a few days. The piercing and bloodsucking apparatus resembles that of the flea, with the difference that the louse has only one pump which sucks blood, and it has no pressure pump for saliva, as the flea has. I think it is doubtful if lice transmit leprosy, as it is shortlived, and would not survive in deserted houses, wherein we know leprosy has sometimes apparently originated. FAGERLUND ${ }^{28}$ reports an interesting case, where a leprosarium nurse, who had to comb the hair of female louse-infected patients, developed in $1 \frac{1}{2}$ years an anaesthetic spot on the left little finger and later macules in various parts of the body. There were no bacilli and the lesions later regressed, leaving anaesthesia.

Doubts about the louse as a vector also extend to the crab louse.

Sarcoptes scabiei. This is certainly one of the insects under suspicion, especially as leprosy and scabies are often associated. INNES $^{29}$ found leprosy and scabies so closely connected in certain parts of East Africa that he came "to accept the amount of scabies in a group as a rough indicator of the incidence of leprosy. Where there is much gross untreated scabies, there is liable to be much 
leprosy in the community, and instances are numerous of the two diseases being coincident in the same person". If the shallow pricks of the tattoo needle transferred leprosy, as in the case reported from Australia and previously mentioned, it would not be surprising if the scabies mites, which operate to a similar depth in the skin, could convey leprosy bacilli.

Cimex lectularius has long been suspected. It does not exist in Iceland, so must be ruled out as a vector there, but it could be so in other countries, for it is a household insect, can live a long time without drawing blood, and frequently attacks people in bed, piercing right into the dermis. SANDES ${ }^{15}$ from his experiments incriminates the bed bug as a possible vector. Cockroaches are nonbiting and therefore much less likely to be vectors. They have not been found in Iceland.

\section{Comments}

Leprosy is first and foremost a housebound disease. Infection in a modern leprosarium never occurs, if the hygienic standard is high and ectoparasites absent. Infections could occur in a leprosarium of lower standards in these things. Cases of purely domiciliary infection, where the patients have moved out, are puzzling but could be explained if arthropods, especially fleas, were vectors. In cases of apparent transmission from person to person by sharing a bed, the case may have been one of latent leprosy, as suggested by FigUERFDo and DESAI ${ }^{30}$ who found acid-fast bacilli in 10\% of apparently sound contacts of leprosy patients. Some latent cases may be expected to develop into recognisable leprosy, some never develop frank lesions.

\section{Conclusion}

In the absence of success in human and animal inoculation experiments, another approach to the problem of the transmission of leprosy is called for. I suggest that choice be made of a limited area or island relatively isolated, with a fair incidence of leprosy. In this area or island a thorough planned effort should be made to eradicate all skin arthropods, particularly in houses occupied or formerly occupied by leprosy subjects. It may have to include the extermination of fleas on cats and dogs and perhaps other animals. Efficient insecticides are now available and the task is not insuperable. Such an experiment would of course include the choice of a control area or island, careful preliminary surveys for leprosy and ectoparasites, and adequate recording and supervision over a long period, say 5 to 10 years or more.

\section{Summary}

The author points out the unsatisfactory state of knowledge of the mode of transmission of leprosy, and thinks that insects cannot 
be ruled out. He reviews work which makes it possible that some of them are at least worth considering, and discusses in this respect fleas and body lice and scabies. He suggests the advisability of planning a field experiment based on the extermination of ectoparasites by modern insecticides.

\section{References}

1. KNOTT, J. Int. Journ. Lepr. (1936), 4, 71.

2. Chaussinand, R. La Lepre. "L'Expansion scientifique Francaise" (1950).

3. BRAY, G. W. ihid. (1934) 2, 319.

4. Fl.oCH, H. ibid. (1951) 19, 283.

5. Botenjamin, R. "Epidemiologisch Onderzoek naar de Betekenis van de Duur en de Aard van het Contact met Lepralijders". University of Indonesia (1949).

6. Marchoux, E. ibid. (1934) 2, 1.

7. Ki.INGimüli.ER, V. "Ergebnisse der Lepraforschung seit 1930". Berlin (1938).

8. PorritT, R. J. \& Olsen, R. E. Int. J. Lepr. (1948) 16, 514.

9. Daniel.ssen, D. C. Festskrift. Bergen (1891).

10. Mouritz, A. A. St. \& Wade, H. W. ibid. (1951) 19, 203.

11. AyCoCK, W. L. \& McKinley, E. B. Int. J. Lepr. (1938) 6, 169.

12. Fennel, A. Int. J. Lepr. (1944) 12, 83.

13. Fagerholm, L. W. Finska Lakreäsällsk. Handlingar (1893) 35, 1.

14. Ehlers, E., Bourret \& With. Bull. de la Societé de Pathol exot. (1911) 4, 239.

15. SANDES, T. L. Lepra (1912) 12, 65.

16. Souza-Araúso, H. C. de. "Memorias do Instituto Oswaldo Cruz 37" (1942) fasc. 2, 95 .

17. Bozrei, A. Annales de l'Institut Pasteur (1909), cited from Ehlers.

18. Duncial, N. Leprosy Review, January 1960.

19. TAl.WIK, S. Lepra (1906) 6, 211.

20. Muños Rivas, G. Rev. de la Facult. de Med. Bogota (1942) 10, 635.

21. Muños Rivas, G. Ammais Brasil. de Derm. e Sifil. (1956) 31, II, 79.

22. MuÑos Rivas, G. "La Transmission de la Lepra. Bogota" (1958).

23. Carrasquilla, J. de Dios. Lepra. Bogota (1905).

24. OKLAND, F. Nordisk Medicin (1957) 57, 751 .

25. SNodgrass, R. E. "The feeding apparatus of biting and sucking insects". Smithsonian Institute. Washington (1944).

26. WENK, P. "Der Kopf von Ctenocephalus canis". Zool. Jahrhucher (1953) 73, 104.

27. WADE, H. W. cfr. ref. no. 10, Mouritz \& Wade.

28. Fagerlund, L. W. Finska Läkaresällsk. Handl. (1925) 67, 636.

29. INNES, R. J. Int. J. Lepr. (1950) 18, 507.

30. Figuerfido, N. \& Desal, S. D. Ind. J. Med. Sciences (1949) 3, 253.

31. Marinusson, S. Nordisk med. Tidsskr. 6, 1095 (1933).

32. BJarnhedinsson, S. Laeknablad (1919) 5, 145. 